\title{
Macro news and long-run volatility expectations
}

ANDERS VILHELMSSON

KNUT WICKSELL WORKING PAPER 2020:1

\section{Working papers}

Editor: A. Vilhelmsson The Knut Wicksell Centre for Financial Studies

Lund University School of Economics and Management

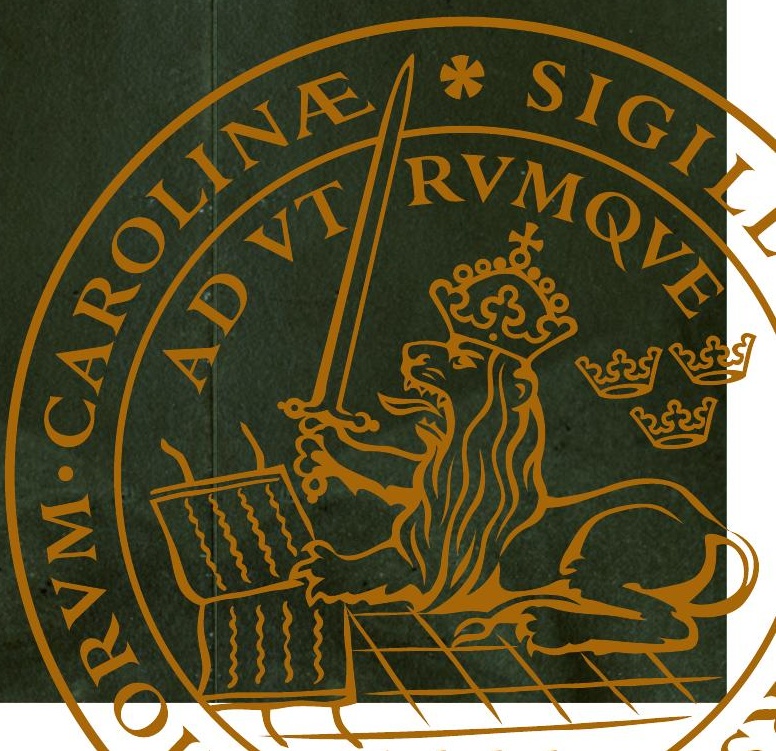





\title{
Macro news and long-run volatility expectations
}

\author{
Anders Vilhelmsson*
}

December 2019

\begin{abstract}
I propose a new model-free method for estimating long-run changes in expected volatility using VIX futures contracts. The method is applied to measure the effect on stock market volatility of scheduled macroeconomic news announcements. I find that looking at long-run changes gives qualitatively different results compared to previous studies that only look at realized variance and the VIX. I further find that FOMC announcements on average resolve uncertainty, but only during times when policy uncertainty is higher than average. Real side macro announcements increase long-run volatility during times of low policy uncertainty, but the effect is reversed during times of high policy uncertainty.
\end{abstract}

\footnotetext{
${ }^{*}$ Department of Economics and Knut Wicksell Centre for Financial Studies, Lund University. I would like to thank Anna Bijelic for excellent research assistance. The Jan Wallanders and Tom Hedelius foundation grant P2016-0010:1 funded the research.
} 


\section{Introduction}

The importance of long term economic uncertainty for asset prices has recently been highlighted in Bansal et al. (2014) and the direct effect of macroeconomic news for asset prices is studied in Gilbert et al. (2017), Savor \& Wilson (2014) as well as Savor \& Wilson (2013). Further, the importance of monetary policy for asset prices is shown in Cieslak et al. (2019). The asset price impact and hence the economic importance of a piece of news depends on both its instantaneous effect on volatility but crucially also on how persistent the change in volatility is as shown already in Poterba \& Summers (1986). Despite this, the volatility persistence of news such as monetary policy announcements and macro economic news has not been much investigated with a notable exception being Li \& Engle (1998). One possible reason is that GARCH and Stochastic Volatility models typically model volatility persistence only as a function of the size (and possibly the sign) of the shock. Thus these models cannot give different persistence to shocks of the same magnitude. This paper develops a new model free measure of the market's ex ante expected volatility during a "long" time period using VIX futures contracts. The measure is used to calculate changes in long run expected volatility around macro economic news announcements.

I find that different macro announcements have different persistence and that accounting for this difference is important for gauging the total impact on volatility. The rank correlation between measuring the importance of the announcements based on the VIX index which looks 30 days ahead and the new measure which looks 180 days ahead is only 
0.6. FOMC announcements with a press conference have the largest impact on long-run volatility and on average FOMC announcements resolve uncertainty. These results are not driven by the FOMC announcements being on average more positive than the market expected since the results remain when controlling for the announcement day stock return to capture surprises.

I further look at heterogeneity of responses resulting from the level of policy uncertainty when the announcement was made. Policy uncertainty is measured by the news based policy uncertainty index of Baker et al. (2016). For real side news (GDP Advance, GDP Preliminary, GDP Final, Industrial Production, Capacity Utilization and the NAPM Index) I find striking differences. When policy uncertainty is low there is a significant increase in expected volatility after the announcements and when policy uncertainty is high I find significant decreases. Also for the FOMC announcement there are differences depending on the level of policy uncertainty. Even though the FOMC announcements lead to a large average decrease in expected volatility this effect is only present when policy uncertainty is higher than average. I further condition on the level of the VIX index to see if it is really policy uncertainty driving the results and not general stock market uncertainty (as captured by the the VIX index) and the results remain.

The remainder of this paper discusses how to measure changes in economic uncertainty and related literature in section 2 , section 3 details my proposed method and section 4 describes the data. Section 5 displays the results and section 6 concludes. 


\section{Measuring changes in economic uncertainty}

\subsection{The ideal measure}

How is stock market uncertainty affected by a news release? I argue that the ideal measure is the difference between the market's ex ante expected volatility for a "long" time period just before and just after the news release. For a news release happening between time $t$ and $t+1$ we thus get

$$
E_{t+1}\left[I V_{t+1, t+\tau+1}\right]-E_{t}\left[I V_{t, t+\tau}\right]=\left[\int_{t+1}^{t+\tau+1} E_{t+1}^{\mathbb{P}}\left(\sigma_{s}^{2}\right) d_{s}\right]-\left[\int_{t}^{t+\tau} E_{t}^{\mathbb{P}}\left(\sigma_{s}^{2}\right) d_{s}\right]
$$

with $I V_{t, t+\tau}$ being the integrated variance (see e.g Andersen et al. (2003)) during time period $[t, t+\tau]$ and $E_{t}^{\mathbb{P}}$ being the conditional expectation at time $t$ under the physical probability measure. Since volatility is often found to have very high persistence, see e.g. Ding et al. (1993) and Baillie (1996), we need to select $\tau$ large to capture the total effect of the news announcement. Note that a related but distinct strand of literature, see Ederington \& Lee (1996) for an early contribution, measures how the realized volatility during the announcement day is affected. Measuring volatility only during the announcement day primarily picks up the market micro-structure effect of how new information in incorporated into prices and says very little about long term uncertainty. For example Chan \& Gray (2018) show that realized volatility typically increases (the market micro-structure effect) whereas option implied volatility typically decreases (resolution of economic uncertainty) during announcement days. 


\section{$2.2 \quad$ Related literature}

There is a very large literature on how macro economic news affect returns and other moments of different asset classes. For brevity I will focus on the studies that measure the impact on variance which is also the object of this paper. Unfortunately eq. (1) is infeasible to implement and the previous literature on the effect of macroeconomic news announcements on volatility can be viewed as different attempts at calculating eq. (1). The earlier strand of literature primarily uses parametric models such as e.g. Li \& Engle (1998), Jones et al. (1998), Flannery \& Protopapadakis (2002) and Brenner et al. (2009). The major drawback with these models is that the full information set as well as the correct functional form is unknown to the econometrician and any econometric model will probably only use a subset of the true conditioning information. Further, a short term increase and a long term decrease in volatility from the same shock as documented by Chan \& Gray (2018) cannot be captured by GARCH type models.

As an alternative to econometric models, expectations can be backed out of observed asset prices. This has a long tradition in volatility forecasting, see e.g. Day \& Lewis (1992) using option prices. Papers that study the effect of macro news on option implied variance include Bailey (1988), Ederington \& Lee (1996), Graham et al. (2003), Beber \& Brandt (2006), Beber \& Brandt (2009), Rosa (2011) as well as Chan \& Gray (2018). These implied measures are however not unproblematic and for the variance forecast literature one obstacle is that the risk neutral and not physical expectation is obtained. Also the literature before Britten-Jones \& Neuberger (2000) had to rely on a specific option pricing 
model to back out volatility. A more practical concern is data availability since out-of-the money options and options with long maturity are typically illiquid. Since the model free method of Britten-Jones \& Neuberger (2000) which also underlies the VIX calculations theoretically require a continuum of strikes the liquidity concern makes it very hard to reliably calculate long maturity volatility from options. Variance swap contracts are an alternative used by Ait-Sahalia et al. (2018) and Amengual \& Xiu (2018). Variance swap prices are however not publicly available. I take the market implied approach in this paper and use option implied variance via the VIX index but importantly I also use the relatively new VIX futures contracts. VIX futures contracts are traded with long maturities and are much more liquid than SP500 index options with corresponding maturities. Further daily VIX futures prices are publicly and freely available.

\section{Method}

\subsection{The VIX index and VIX futures}

The VIX index, which is constructed by CBOE, measures the square-root of the risk neutral expected variance of the S\&P 500 index according to

$$
V I X_{t}=100 \cdot \sqrt{\frac{365}{30} \int_{t}^{t+30} E_{t}^{\mathbb{Q}}\left(\sigma_{s}^{2}\right) d s}
$$

by using a weighted average of S\&P 500 index options with different maturity to construct an artificial contract with a maturity of one month (22 trading days). The construction 
of the index is described in detail in e.g. Dupoyet et al. (2011).

The VIX is sometimes loosely interpreted as the market's expected 30 day ahead standard deviation. This is wrong for two reasons. The first reason is the measure change; there is a difference between risk neutral and physical volatility (the volatility risk premium) and it is found substantial in e.g. Carr \& Wu (2008) and Bollerslev et al. (2009). The second reason is convexity, since VIX is the square root of the expected variance, Jensen's inequality implies that the VIX is higher than the risk neutral expected standard deviation. To be able to look at a much longer time horizon than the 30 days afforded by the VIX I use VIX futures contracts. A VIX futures contract is a financial derivative that has the VIX index as the underlying security. Such a contract's time $t$ price $^{1}$ with maturity date $T$ is given by

$$
F_{t, T}=E_{t}^{\mathbb{Q}}\left[V I X_{T}\right]=\sqrt{\frac{365}{30} \int_{T}^{T+30} E_{t}^{\mathbb{Q}}\left(\sigma_{s}^{2}\right) d s}
$$

Note that the expectation is taken at time $t$ but the price of the contract depends on the integrated variance during the time period $[T, T+30]$ since the VIX itself is future looking so e.g. the pay-off from a VIX futures contract maturing 150 days from now will give the square root of the market's risk neutral expected variance during the time period $[150,180]$

\footnotetext{
${ }^{1}$ Price in this context refers to the price of the underlying that the buy side of the futures contract agrees to pay, this is set so that the price of the actual contract is always zero.
} 


\subsection{Estimating changes in expectations}

The prices of VIX futures contracts can be used to extract information about the markets ex ante expected variance. If the underlying asset is traded no arbitrage gives the well known cost-of-carry relationship

$$
F_{t, T}=S_{t} \exp [(r+s)(T-t)]
$$

with $S_{t}$ being the spot price, $r$ the continuously compounded interest rate and $s$ the storage cost. In this case the futures price holds no information about future expectations that are not already incorporated into the spot price. The VIX however is not traded and therefore the above arbitrage relationship for the futures price does not hold. No single accepted model for pricing VIX futures exists but all models, that incorporate mean reversion in the VIX, have in common that the delta of a VIX futures contract $\left(F_{\Delta}\right)$ will be a function of the mean reversion speed of the VIX and of the time remaining to maturity. Figure 1 shows the change in all outstanding VIX futures on the 20th of August 2015 and the 24th of June 2014, the first circle at days to maturity zero corresponds to the VIX index and the other circles are VIX futures contracts with different time to maturity. As can be seen from the figure there is a very clear pattern of a decreasing delta as the time to maturity increases, this pattern is generally more clear the larger the change in VIX.

[Insert figure 1 about here]

Instead of relying on a specific pricing model for the VIX futures contract I empirically 
estimate how the change in futures price at a given day $(t)$ depends on the contracts time to maturity assuming a log-linear relationship between the price change and time to maturity. This is done using all outstanding contracts (n) each day (t)

$$
\left(F_{n, t+1}-F_{n, t}\right)-\Delta V I X_{t+1}=b_{t} \cdot \ln (T-t)+\varepsilon_{n, t}
$$

for $(T-t) \geq 1$. Subtracting the change in VIX $(\Delta V I X)$ and estimating without a constant forces the intercept (when time to maturity is zero) to exactly fit the change in VIX. This incorporates the no arbitrage condition that the futures price has to equal the VIX index at maturity. Since I model the change in the futures price directly instead of modelling the level, the variance risk premium that affects the futures prices will only have a small effect on the results. More specifically, the measure will only include the change in the variance risk premium between $t$ and $t+1$ so a constant additive variance risk premium will not have any impact.

The next step is to compute the expected change in the VIX index each day for all $\tau$

$$
E_{t+1}^{\mathbb{Q}}\left[V I X_{t+1, t+\tau+1}\right]-E_{t}^{\mathbb{Q}}\left[V I X_{t, t+\tau}\right]=\frac{1}{\tau}\left(\Delta V I X_{t+1}+\sum_{s=1}^{\tau}\left[b_{t} * \log (s)\right]\right)
$$

with $\tau=150$. I pick want to pick $\tau$ as large as possible but at the same time avoid interpolating outside the data range. The choice $\tau=150$ is the largest value that is also always smaller than the maturity of the longest dated futures contract. Conceptually we can think of equation (3) as being the average change in VIX futures contracts maturating 
each day for the coming 150 days and eq. (3) interpolates the price change for days when no contract exists. Equivalently we can think of as equation (3) as the change in the VIX term structure, henceforth $\Delta V T S$. One alternative would of course be to only use price changes for those VIX futures contracts that actually exist. However, that would make it impossible to compare different days to each other, since the time to maturity of the contracts is different on different days, we would compare different parts of the VIX term structure. The interpolation scheme ensures comparability since we always compare contracts (though many interpolated) with the same maturity. The term $\Delta V I X_{t+1}$ in eq. (3) is the expected change in the spot VIX $(s=0)$.

[Insert figure 2 about here]

Figure (2) shows four different days where the first circle is the change in VIX and the other circles are the changes in the outstanding futures contracts. The solid line is $\Delta V I X_{t+1}+b_{t} * \log (\mathbf{s})$ with $\mathbf{s}$ the vector of integers from 1 to $\tau$. The (discretizised) area under the line (normalized by $1 / \tau$ ) is given by $(3)$.

\section{Data}

Futures contracts with the VIX index as the underlying asset started trading March 26, 2004 with a monthly expiration. The futures contract expires on the Wednesday that is 30 days prior to the third Friday of the calendar month immediately following the month in which the contract expires. For most of the sample period eight contracts are 
trading at the same time with maturities in the eight coming calendar months. In 2015 six contracts with a weekly maturity schedule where introduced giving a total number of 14 simultaneously traded contracts with different maturity. For the VIX futures contract all available data is used until year end 2018. The traded volume in the different futures contract differs and in general, liquidity was poor in the first years of trading. The contract with shortest maturity typically has the largest volume. To avoid illiquid prices I require a daily volume of at least 200 contracts and that at least 4 contracts with this volume is traded $^{2}$. The total number of days in the sample is 3,773 and the filter excludes a total number of 492 days. Excluded days are by far most common in the early part of the sample with 204 days missing in 2004, 182 in 2005, 90 in 2006 and only 16 in all other years taken together. The average traded volume in the contracts per day are 352 in 2004, 1,734 in 2006, 17,571 in 2010 and more than 100,000 each day for every year since 2013. For contracts with a maturity $>100$ days the numbers for the same years are 37, 204, 860, and around 10,000 per day every year since 2013. The futures returns are matched to daily returns from the SP500 index and to the VIX index.

Based on previous literature I use 22 different macro news releases, the dates for the releases are taken from Bloomberg's economic calendar. The specific announcements are given in Table 1. For exact release times during the day and release day during the month see Gilbert et al. (2017). Since april 2011 four of the eight yearly FOMC announcements

\footnotetext{
${ }^{2}$ The VIX futures contract has the VIX times 1000 dollars as the underlying so with an average VIX value of around 15, 200 contracts correspond to a traded value of 3 Million dollars. The Mini VIX futures that were traded from 2009 to 2014 had the VIX times 100 USD as the underlying, they are not included in the sample.
} 
have a pre-scheduled press conference. I treat these as separate announcements since Boguth et al. (2019) show that media coverage and the market's implied probability of a rate change is higher for FOMC announcements with a press conference.

Three of the macro announcements are joint effects of two announcements, these effects cannot be estimated separately since the announcements are always done on the same day. Specifically Industrial production also includes Capacity utilization, Personal consumption expenditures includes the effects of Personal income and Factory orders includes the effect of durable goods orders.

\section{Results}

\subsection{Descriptives}

Table 1 shows average stock market returns, changes in VIX and changes in the VTS for all macro announcements individually and for all days with any macro announcements. In total there are 2,286 days in the sample of which 1,349 has at least one macro announcement. The annualized stock market return is $13.7 \%$ on announcement days compared to $8.5 \%$ on all days. For FOMC announcement days the stock market return is very high at $44.5 \%$ and on announcement days with a press conference even higher at $81.7 \%$ which is in line with the findings in Lucca \& Moench (2015) who show that $80 \%$ of the equity risk premium is realized during the 24 hours before FOMC announcements. FOMC announcements with a press conference also have the largest impact both on VIX and the VTS with 
an average change of -0.88 for the VIX and -0.28 for the $\mathrm{VTS}^{3}$. The results are consistent with $\mathrm{Hu}$ et al. (2019) who suggest that large announcement returns are due to build up of uncertainty that is rapidly resolved after the announcement. For example out of the five announcements with the largest returns (FOMC PC, GDP Preliminary, Trade balance, FOMC and NAPM index) four are in the top five of also having the largest reduction in $\triangle V T S$. However this results could also be explained by the announcements being on average better than the market expected which would also lead to both increased returns and decreased future volatility. However, at least for the FOMC it is well documented by Lucca \& Moench (2015) that the positive returns accrue before the announcement (pre-announcement drift) and returns just at and after the announcement are very close to zero. According to Kurov et al. (2019) there is no pre-announcement drift for GDP preliminary or the trade balance but there is for the NAPM index.

To gauge the relative importance of the announcements I rank them based on the absolute value of the average change in VIX and VTS respectively.

\section{[Insert Table 1 about here]}

Generally the VIX and the VTS will rank the importance of the different announcements differently as shown by a rank correlation of 0.60 . The differences will be most pronounced for announcements that have a very high or low persistence. For example the

\footnotetext{
${ }^{3}$ Note that the magnitudes are not comparable between the VIX and the VTS even when both are scaled to yearly percentage standard deviation. This is because VTS measures the average effect of a change in a 180-day volatility which will be smaller than the average change in a 30-day volatility when volatility is mean reverting.
} 
NAPM index gives one of the most persistent changes in volatility resulting in it to be ranked 10th by the VTS but only 15 th by the VIX. The VIX underestimates it's total impact since it only looks at changes for the first 30 days. The VIX judges the Consumer price index to be almost equally important (ranked 16th) as the NAPM index whereas the consumer price index is only ranked 20th by the VTS due to its much lower persistence, as seen in Figure (3). Persistence is measures as the half-life of the change in VIX on the announcement day, e.g. Nonfarm payroll employment leads to an average change in VIX of 0.2 and after ten days the average change is 0.1 so it has a half-life of 10 days. For the NAPM index the change in the VTS is still larger than half the change in VIX after 150 days, this is also true for Construction spending and the index of leading indicators. GDP advance has a very short half-life of only 7 days resulting in a ranking based on VIX of 11 and 23 by the VTS.

[Insert figure 3 about here]

\subsection{Controlling for surprises}

One potential problem with just looking at descriptive statistics is that the effect of the announcement and the surprise component of the announcement is measured simultaneously. We can think of the effect of the announcement as replacing the market's expected distribution of possible values to a single value, so e.g. even if the market's average expectation for the GDP announcement was correct we still expect a change in variance since the uncertainty has now been resolved. However if the GDP announcement was also 
surprising we get both the effect of the surprise which may increase or decrease volatility plus the effect of the resolution of uncertainty. To control for the surprise component I use the same day return of the SP500 index as a control variable and run regressions of the form

$$
\Delta V T S_{t}=\alpha+\beta \cdot \operatorname{ret}_{t}+\boldsymbol{\theta} \mathbf{I}+\varepsilon_{t}
$$

here $\boldsymbol{\theta}$ is a vector of coefficients (one for each macro announcement) and $\mathbf{I}$ is a matrix of dummy variables taking the value of one if a particular macro announcement was made on a given day. When controlling for the surprise we should get a cleaner measure of the importance of the different macro announcements since even given rational expectations the surprise component may be on average positive or negative for a given announcement during our relatively short period sample period of 14 years. For example it is hard to explain the average stock market return of $59 \%$ for the GDP Preliminary announcement if the numbers were not better than expected on average during the 36 announcements in the sample.

[Insert Table 2 about here]

As expected the coefficient for the same day return is negative (good news reduce volatility or reduced volatility is good news), is is also very significant and explains almost $70 \%$ of the variation in changes in VIX and VTS. Columns one and two of table 2 the results without controlling for the same day return. FOMC PC shows the additional effect of FOMC when there is a press conference, for VTS the effect is jointly significant 
at the $10 \%$ level and for VIX at the $5 \%$ level. When controlling for same period returns in columns 3 and 4 the joint effect is significant at the $5 \%$ for the VIX but not for VTS. Even though most macro announcements are not individually significant their joint effect may still be important and we hence group macro announcements according to Beechey \& Wright (2009).

[Insert table 3 about here]

Table 3 shows the effect of price news (PPI and Consumer Price Index), real side news (GDP Advance, GDP Preliminary, GDP Final, Industrial Production, Capacity Utilization and the NAPM Index) monetary policy news (the FOMC with or without a press conference) as well as "any news" which is an indicator variable taking the value of one if there is at least one scheduled announcement during that day. Monetary policy news have a significant negative effect on the VTS at the $5 \%$ level without controlling for same period returns and at the $10 \%$ level when controlling for returns. When controlling for returns also price news are significant at the $10 \%$ level but the effect of real side news is small and insignificant. When looking at the average effect of all announcements taken together the effect is very small and insignificant.

Law et al. (2018) show that the stock return reaction to macro news has a cyclical variation and Beber \& Brandt (2009) as well as Chuliá et al. (2010) find that volatility increases more during recessions than expansions. To study this I proceed by looking at how the effect of announcements differ depending on the policy uncertainty measured by the news based policy uncertainty index of Baker et al. (2016). 


\subsection{Macro news and policy uncertainty}

In table $4 \mathrm{I}$ interact the policy uncertainty index with the different groups of macro announcements according to

$$
\Delta V T S_{t}=\alpha+\beta \cdot \text { ret }_{t}+\boldsymbol{\theta} \mathbf{I}+\phi \mathbf{I} \cdot \text { Policy }+\gamma \mathbf{I} \cdot V I X+\varepsilon_{t}
$$

here $\mathbf{I}$ is a matrix of indicator variable that takes the value of one for each of the groups price news, real side news and monetary policy news if any announcement in one of the groups was made on a given day. The announcements are interacted with policy uncertainty (Policy) and with the VIX index. $\beta$ is a scalar coefficient and $\boldsymbol{\theta}, \boldsymbol{\phi}$ and $\boldsymbol{\gamma}$ are vectors of coefficients. Interestingly there is a strong negative interaction between real side news and policy uncertainty as seen in table 4. When controlling for same period returns the interaction is significant at the $1 \%$ level and there is also an interaction between policy uncertainty and monetary policy news significant at the $10 \%$ level. However the total marginal effects are best illustrated graphically as figure 4 very clearly shows that real side news has a positive and significant impact on VTS when policy uncertainty is low and a negative and significant impact when policy uncertainty is high.

$$
\text { [Insert figure } 4 \text { about here] }
$$

This shift in sign of the effect mask the impact of real side news in the previous analysis since the positive and negative effects almost cancel out. Further we can see in figure 5 that FOMC announcements only decrease the VTS when policy uncertainty is high, for 
values at around 140 and higher there is a significant negative effect but there is no effect when policy uncertainty is low.

[Insert figure 5 about here]

Hu et al. (2019) suggest that the high return before the FOMC announcement is a risk premium for uncertainty that is resolved after the announcement, if this suggestion is correct then there should be much lower FOMC returns during low policy uncertainty announcements than during periods of high policy uncertainty announcements since uncertainty is not resolved during low policy uncertainty days. To test this implication of Hu et al. (2019) I calculate FOMC returns for announcement days split on when policy uncertainty is higher or lower than 100. Somewhat surprisingly and in contrast to the prediction by $\mathrm{Hu}$ et al. (2019) I find that the FOMC percentage annualized returns are $101 \%$ on FOMC announcement days with low policy uncertainty (45 days) and $46 \%$ on days with high uncertainty (75 days).

[Insert table 4 about here]

For price news as seen in figure 6, there is no significant impact on the VTS independent of the level of the policy uncertainty.

[Insert figure 6 about here]

To see if it is really policy uncertainty driving the results and not general stock market uncertainty (captured by the the VIX index) I add the VIX as an explanatory variable 
in column 3, the results are almost identical. In specification four I also simultaneously interact the announcements with both the policy uncertainty index and the VIX index. The interaction effect for real side news is a bit smaller but still large and significant whereas the interaction between real side news and VIX is insignificant. For monetary policy news on the other hand the interaction with VIX decrease the importance of the interaction with the policy uncertainty index and about half the effect is instead captured by the interaction with the VIX.

\section{Conclusion}

This paper proposes a new model free way of measuring long term changes in the market's expectations of future variance. I show that shocks to expected volatility resulting from different macro news differ in economic importance not only based on the size of the shock but importantly also based on how persistent the shock is. Using the VIX to look 30 days ahead as done previously in the literature is not enough to capture the difference in persistence. The rank correlation between the VIX and the $\Delta V T S$ measure proposed in this paper is only 0.60. Further it is found crucial to condition on the level of policy uncertainty when measuring the impact of macro news announcements. In times with low uncertainty, real side news increase future volatility whereas in times of high policy uncertainty, real side news decrease future volatility. 


\section{References}

Ait-Sahalia, Y., Karaman, M. \& Mancini, L. (2018), 'The term structure of variance swaps and risk premia', Swiss Finance Institute Research Paper (18-37).

Amengual, D. \& Xiu, D. (2018), 'Resolution of policy uncertainty and sudden declines in volatility', Journal of Econometrics 203(2), 297-315.

Andersen, T. G., Bollerslev, T., Diebold, F. X. \& Labys, P. (2003), 'Modeling and forecasting realized volatility', Econometrica 71(2), 579-625.

Bailey, W. (1988), 'Money supply announcements and the ex ante volatility of asset prices', Journal of Money, Credit and Banking 20(4), 611-620.

Baillie, R. T. (1996), 'Long memory processes and fractional integration in econometrics', Journal of econometrics 73(1), 5-59.

Baker, S. R., Bloom, N. \& Davis, S. J. (2016), 'Measuring economic policy uncertainty', The quarterly journal of economics 131(4), 1593-1636.

Bansal, R., Kiku, D., Shaliastovich, I. \& Yaron, A. (2014), 'Volatility, the macroeconomy, and asset prices', The Journal of Finance 69(6), 2471-2511.

Beber, A. \& Brandt, M. W. (2006), 'The effect of macroeconomic news on beliefs and preferences: Evidence from the options market', Journal of Monetary Economics 53(8), 1997-2039. 
Beber, A. \& Brandt, M. W. (2009), 'When it cannot get better or worse: The asymmetric impact of good and bad news on bond returns in expansions and recessions', Review of Finance 14(1), 119-155.

Beechey, M. J. \& Wright, J. H. (2009), 'The high-frequency impact of news on long-term yields and forward rates: Is it real?', Journal of Monetary Economics 56(4), 535-544.

Boguth, O., Grégoire, V. \& Martineau, C. (2019), 'Shaping expectations and coordinating attention: The unintended consequences of fomc press conferences', Journal of Financial and Quantitative Analysis 54(6), 2327-2353.

Bollerslev, T., Tauchen, G. \& Zhou, H. (2009), 'Expected stock returns and variance risk premia', The Review of Financial Studies 22(11), 4463-4492.

Brenner, M., Pasquariello, P. \& Subrahmanyam, M. (2009), 'On the volatility and comovement of us financial markets around macroeconomic news announcements', Journal of Financial and Quantitative Analysis 44(6), 1265-1289.

Britten-Jones, M. \& Neuberger, A. (2000), 'Option prices, implied price processes, and stochastic volatility', The Journal of Finance 55(2), 839-866.

Carr, P. \& Wu, L. (2008), 'Variance risk premiums', The Review of Financial Studies $22(3), 1311-1341$.

Chan, K. F. \& Gray, P. (2018), 'Volatility jumps and macroeconomic news announcements', Journal of Futures Markets 38(8), 881-897. 
Chuliá, H., Martens, M. \& van Dijk, D. (2010), 'Asymmetric effects of federal funds target rate changes on s\&p100 stock returns, volatilities and correlations', Journal of Banking E Finance 34(4), 834-839.

Cieslak, A., Morse, A. \& Vissing-Jorgensen, A. (2019), 'Stock returns over the fomc cycle', The Journal of Finance 74(5), 2201-2248.

Day, T. E. \& Lewis, C. M. (1992), 'Stock market volatility and the information content of stock index options', Journal of Econometrics 52(1-2), 267-287.

Ding, Z., Granger, C. W. \& Engle, R. F. (1993), 'A long memory property of stock market returns and a new model', Journal of empirical finance 1(1), 83-106.

Dupoyet, B., Daigler, R. T. \& Chen, Z. (2011), 'A simplified pricing model for volatility futures', Journal of Futures Markets 31(4), 307-339.

Ederington, L. H. \& Lee, J. H. (1996), 'The creation and resolution of market uncertainty: the impact of information releases on implied volatility', Journal of Financial and Quantitative Analysis 31(4), 513-539.

Flannery, M. J. \& Protopapadakis, A. A. (2002), 'Macroeconomic factors do influence aggregate stock returns', The review of financial studies 15(3), 751-782.

Gilbert, T., Scotti, C., Strasser, G. \& Vega, C. (2017), 'Is the intrinsic value of a macroeconomic news announcement related to its asset price impact?', Journal of Monetary Economics 92, 78-95. 
Graham, M., Nikkinen, J. \& Sahlström, P. (2003), 'Relative importance of scheduled macroeconomic news for stock market investors', Journal of Economics and Finance 27(2), 153-165.

Hu, G. X., Pan, J., Wang, J. \& Zhu, H. (2019), Premium for heightened uncertainty: Solving the fomc puzzle, Technical report, National Bureau of Economic Research.

Jones, C. M., Lamont, O. \& Lumsdaine, R. L. (1998), 'Macroeconomic news and bond market volatility', Journal of Financial Economics 47(3), 315-337.

Kurov, A., Sancetta, A., Strasser, G. \& Wolfe, M. H. (2019), 'Price drift before us macroeconomic news: Private information about public announcements?', Journal of Financial and Quantitative Analysis 54(1), 449-479.

Law, T. H., Song, D. \& Yaron, A. (2018), 'Fearing the fed: How wall street reads main street', Available at SSRN 3092629 .

Li, L. \& Engle, R. F. (1998), 'Macroeconomic announcements and volatility of treasury futures'.

Lucca, D. O. \& Moench, E. (2015), 'The pre-fomc announcement drift', The Journal of Finance 70(1), 329-371.

Poterba, J. M. \& Summers, L. H. (1986), 'The persistence of volatility and stock market fluctuations', The American Economic Review 76(5), 1142-1151. 
Rosa, C. (2011), 'Words that shake traders: The stock market's reaction to central bank communication in real time', Journal of Empirical Finance 18(5), 915-934.

Savor, P. \& Wilson, M. (2013), 'How much do investors care about macroeconomic risk? evidence from scheduled economic announcements', Journal of Financial and Quantitative Analysis 48(2), 343-375.

Savor, P. \& Wilson, M. (2014), 'Asset pricing: A tale of two days', Journal of Financial Economics 113(2), 171-201. 


\section{Tables and figures}

Figure 1: Price changes in VIX futures
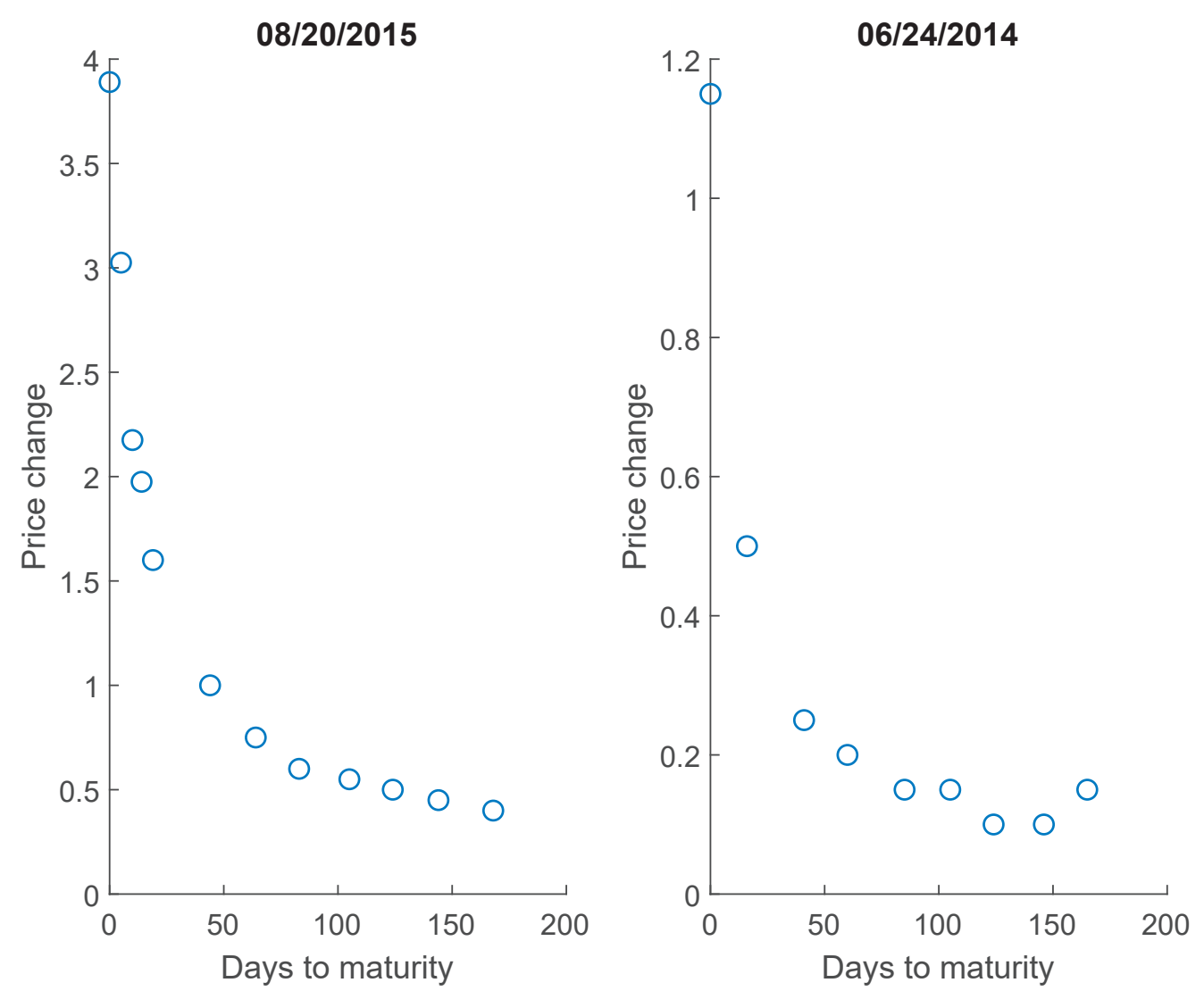

This figure shows the change in VIX (leftmost circle) and changes in the VIX futures contracts with different times to maturity on August 20th 2015 (left) and June 24th 2014 (right). 
Figure 2: Fitted price changes in VIX futures
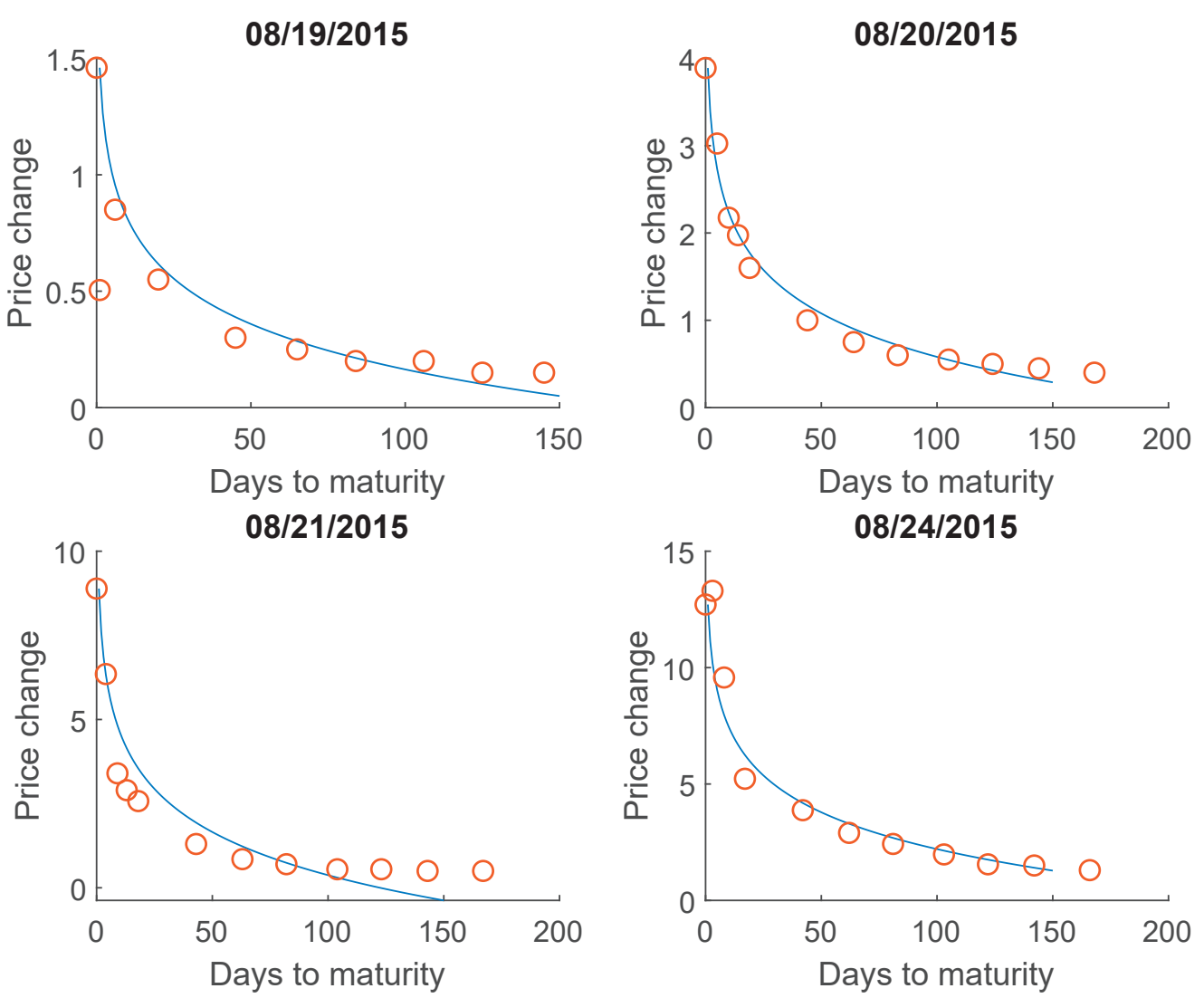

This figure shows eq (2) fitted to the changes in futures prices for August 19, 2015 (top left) August 20,2015 (top right), August 21, 2015 (bottom left) and August 24, 2015 (bottom right) 
Figure 3: Average impact of CPI vs NAPM

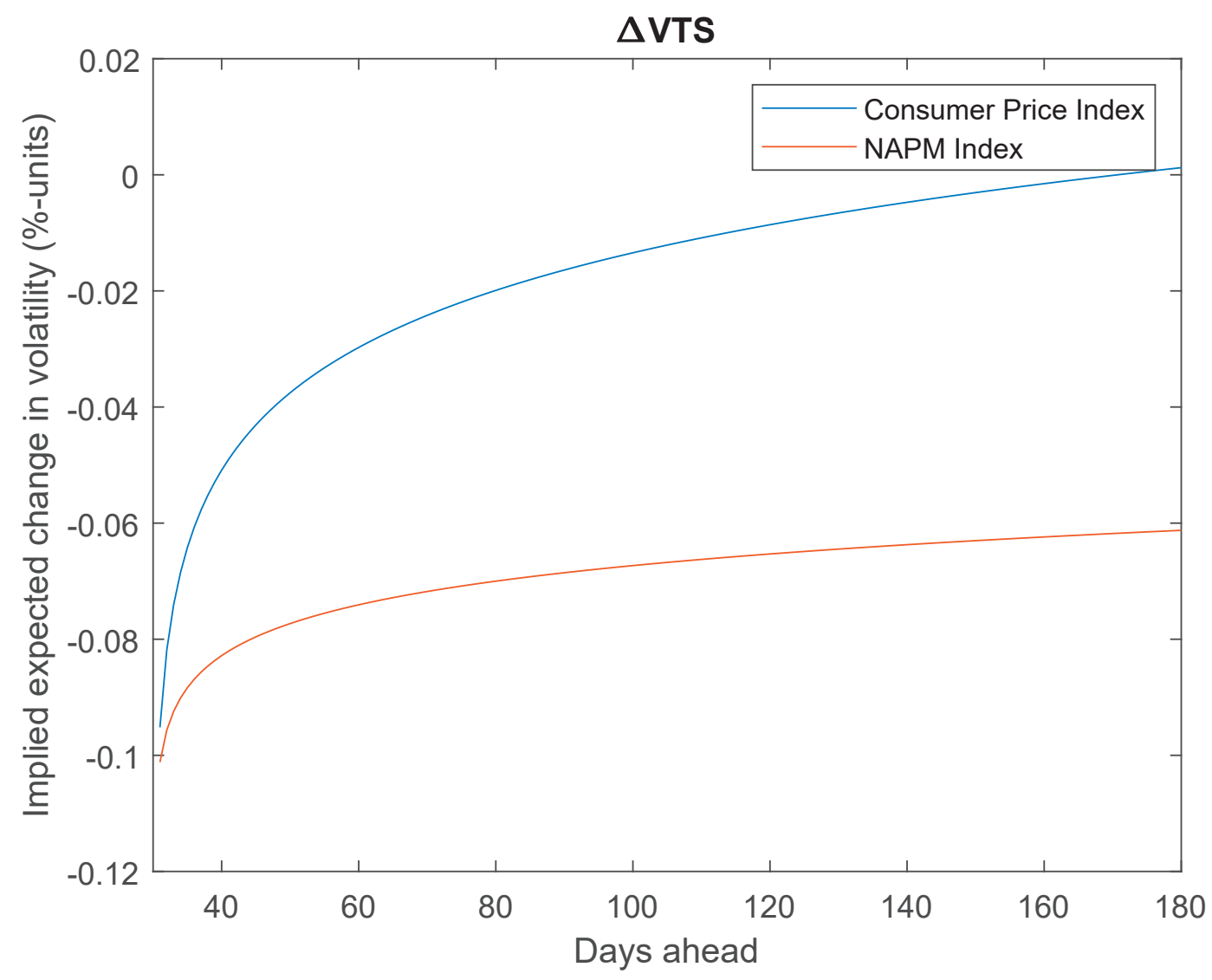

This figure shows $\triangle$ VTS for the Consumer price index and the NAPM index. As measured by the VIX (the leftmost point on the curve) the impact would seem equal but changes from the NAPM index announcements are much more persistent which is captured by $\Delta \mathrm{VTS}$. 
Figure 4: Realside news and Policy uncertainty

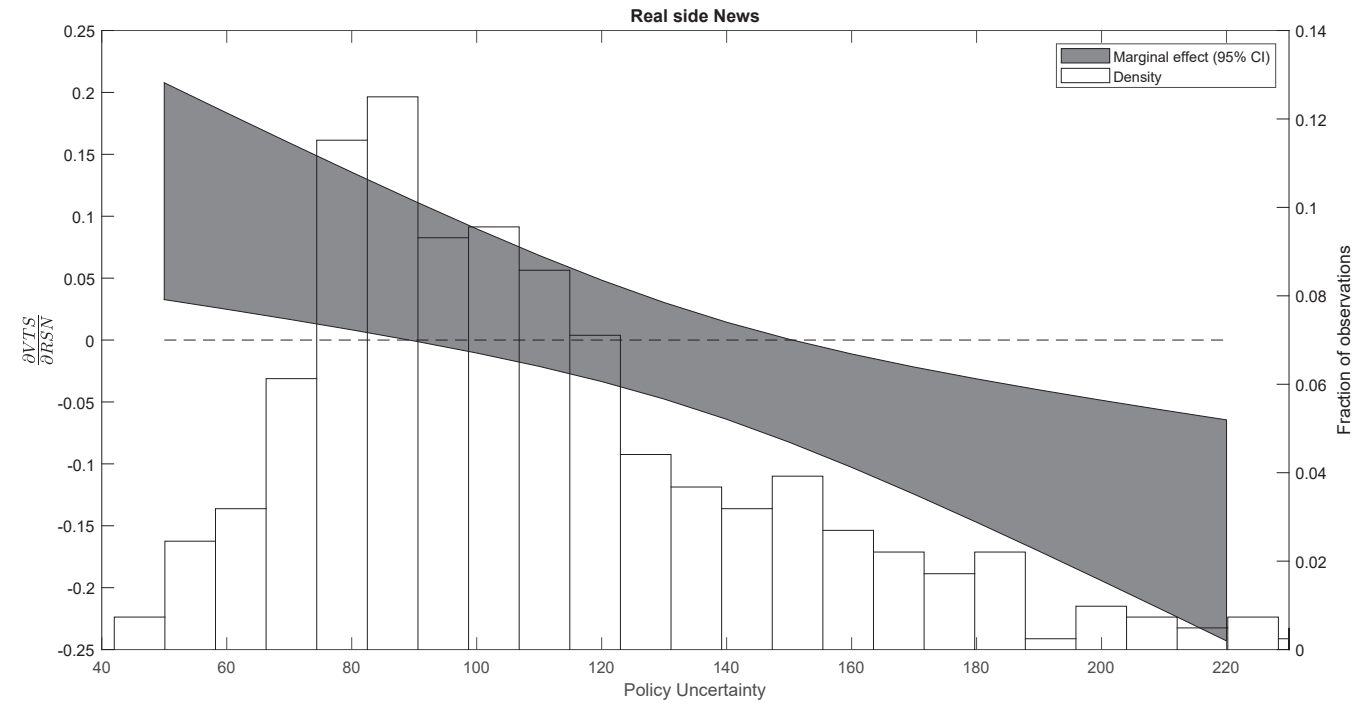

This figure shows the marginal effect (scale on the left) based on the regression results from column 2 in Table 4 for different levels of policy uncertainty as measured by the news based policy uncertainty index of Baker et al. (2016). The grey shaded area shows a $95 \%$ confidence interval for the marginal effect. The histogram in the background shows the distribution of the policy uncertainty index (scale on the right). 
Figure 5: FOMC announcements and Policy uncertainty

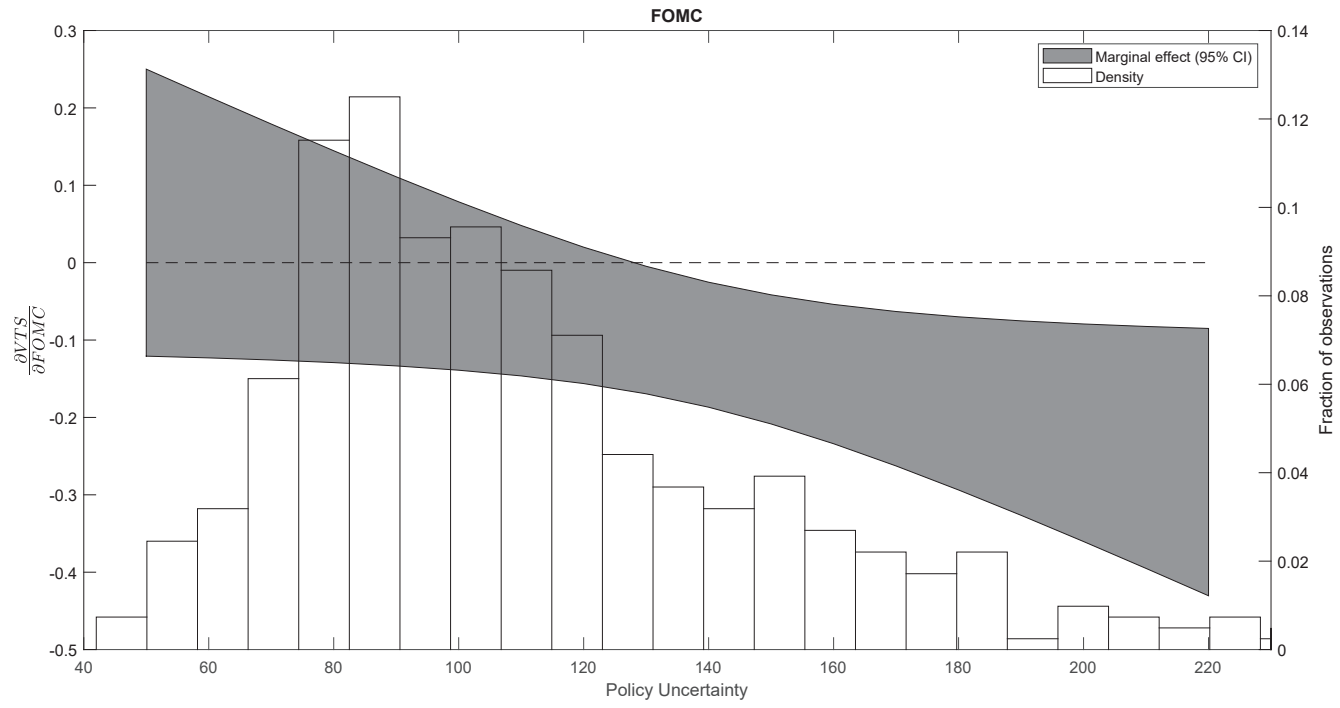

This figure shows the marginal effect (scale on the left) based on the regression results from column 2 in Table 4 for different levels of policy uncertainty as measured by the news based policy uncertainty index of Baker et al. (2016). The grey shaded area shows a $95 \%$ confidence interval for the marginal effect. The histogram in the background shows the distribution of the policy uncertainty index (scale on the right). 
Figure 6: Price news news and Policy uncertainty

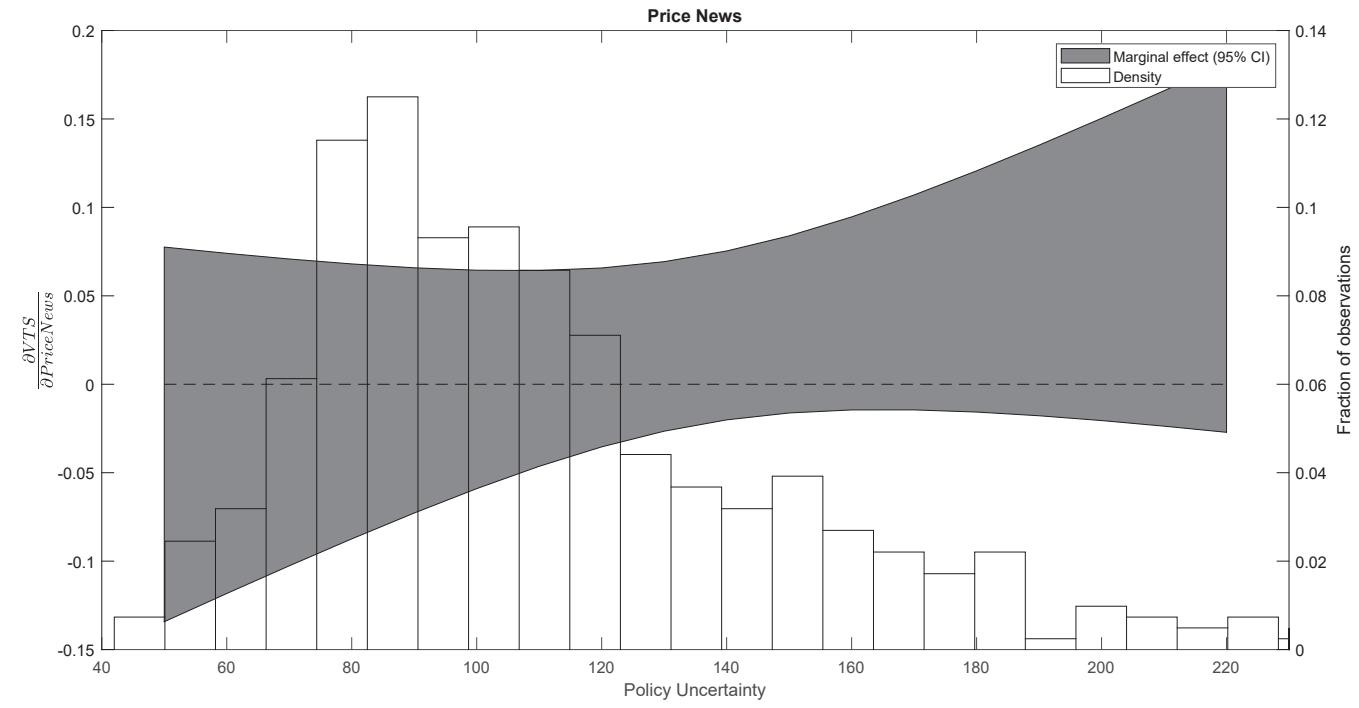

This figure shows the marginal effect (scale on the left) based on the regression results from column 2 in Table 4 for different levels of policy uncertainty as measured by the news based policy uncertainty index of Baker et al. (2016). The grey shaded area shows a $95 \%$ confidence interval for the marginal effect. The histogram in the background shows the distribution of the policy uncertainty index (scale on the right). 


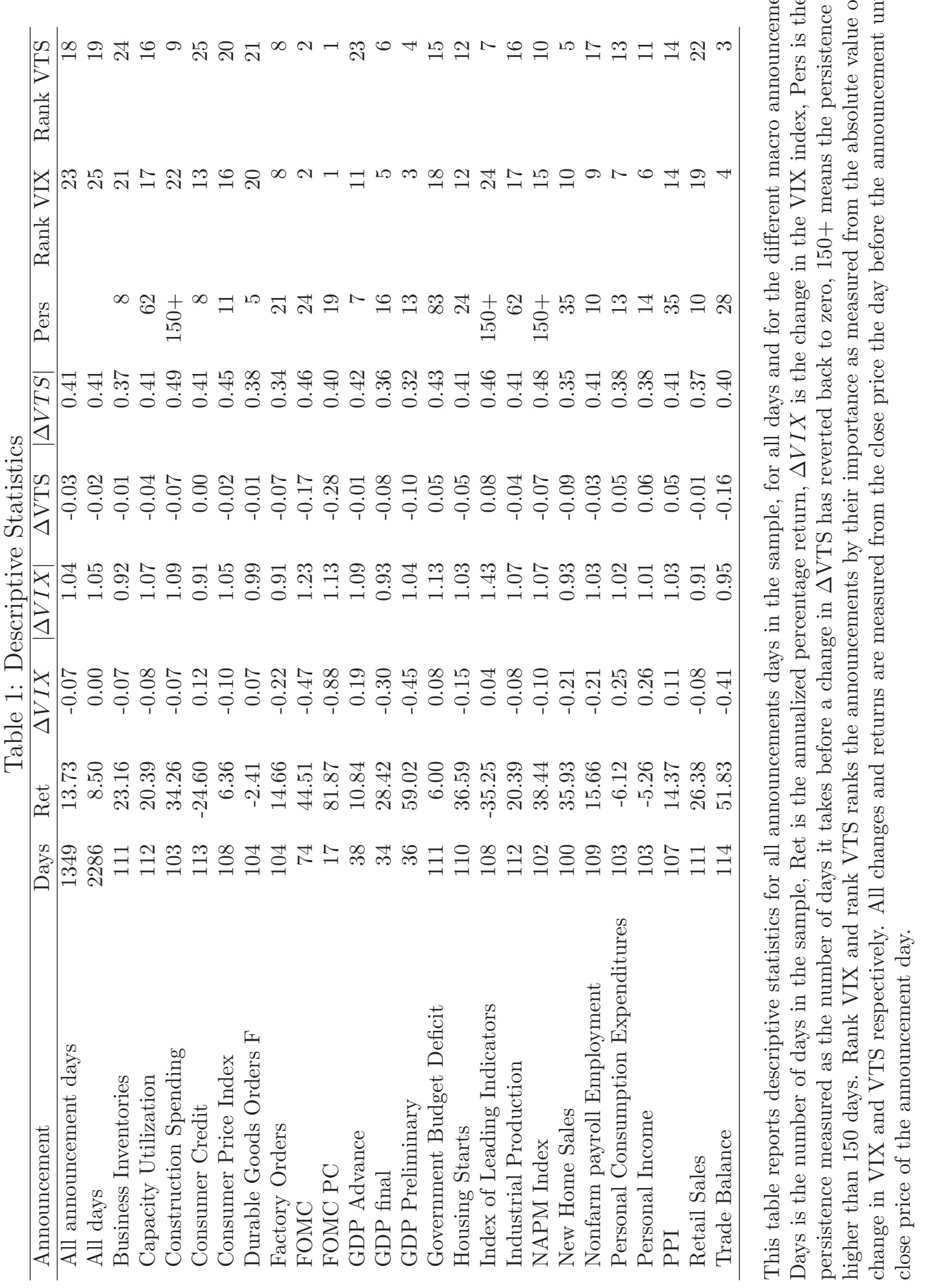


Table 2: Regression results individual Macro announcements

\begin{tabular}{|c|c|c|c|c|}
\hline VARIABLES & $\begin{array}{c}(1) \\
\Delta \text { VTS }\end{array}$ & $\begin{array}{c}(2) \\
\Delta \text { VIX }\end{array}$ & $\begin{array}{c}(3) \\
\Delta \mathrm{VTS}\end{array}$ & $\begin{array}{c}(4) \\
\Delta \text { VIX }\end{array}$ \\
\hline return & & & $\begin{array}{c}-0.00210^{* * *} \\
(2.94 \mathrm{e}-05)\end{array}$ & $\begin{array}{r}-0.00576^{* * *} \\
(8.17 \mathrm{e}-05)\end{array}$ \\
\hline GDPAdvance & $\begin{array}{l}0.0325 \\
(0.104)\end{array}$ & $\begin{array}{c}0.192 \\
(0.287)\end{array}$ & $\begin{array}{c}0.0455 \\
(0.0578)\end{array}$ & $\begin{array}{c}0.228 \\
(0.161)\end{array}$ \\
\hline GDPPreliminary & $\begin{array}{c}-0.0819 \\
(0.106)\end{array}$ & $\begin{array}{c}-0.510^{*} \\
(0.293)\end{array}$ & $\begin{array}{c}0.0378 \\
(0.0590)\end{array}$ & $\begin{array}{l}-0.182 \\
(0.164)\end{array}$ \\
\hline GDPFinal & $\begin{array}{l}-0.0821 \\
(0.109)\end{array}$ & $\begin{array}{l}-0.386 \\
(0.301)\end{array}$ & $\begin{array}{l}-0.0134 \\
(0.0606)\end{array}$ & $\begin{array}{l}-0.197 \\
(0.169)\end{array}$ \\
\hline NonfarmPayrollEmployment & $\begin{array}{l}0.00360 \\
(0.0657)\end{array}$ & $\begin{array}{l}-0.255 \\
(0.181)\end{array}$ & $\begin{array}{c}0.0364 \\
(0.0365)\end{array}$ & $\begin{array}{l}-0.165 \\
(0.101)\end{array}$ \\
\hline RetailSales & $\begin{array}{l}-0.296 \\
(0.447)\end{array}$ & $\begin{array}{l}-0.398 \\
(1.232)\end{array}$ & $\begin{array}{l}0.0814 \\
(0.248)\end{array}$ & $\begin{array}{c}0.639 \\
(0.689)\end{array}$ \\
\hline IndustrialProduction & $\begin{array}{l}-0.0294 \\
(0.0646)\end{array}$ & $\begin{array}{r}-0.0790 \\
(0.178)\end{array}$ & $\begin{array}{c}-0.00730 \\
(0.0358)\end{array}$ & $\begin{array}{l}-0.0184 \\
(0.0996)\end{array}$ \\
\hline PersonalIncome & $\begin{array}{c}0.0996 \\
(0.0647)\end{array}$ & $\begin{array}{c}0.265 \\
(0.178)\end{array}$ & $\begin{array}{l}0.0639^{*} \\
(0.0359)\end{array}$ & $\begin{array}{c}0.167^{*} \\
(0.0999)\end{array}$ \\
\hline ConsumerCredit & $\begin{array}{c}0.0407 \\
(0.0644)\end{array}$ & $\begin{array}{c}0.197 \\
(0.177)\end{array}$ & $\begin{array}{l}-0.0376 \\
(0.0357)\end{array}$ & $\begin{array}{l}-0.0183 \\
(0.0994)\end{array}$ \\
\hline NewHomeSales & $\begin{array}{l}-0.0786 \\
(0.0660)\end{array}$ & $\begin{array}{l}-0.284 \\
(0.182)\end{array}$ & $\begin{array}{l}0.00178 \\
(0.0367)\end{array}$ & $\begin{array}{c}-0.0628 \\
(0.102)\end{array}$ \\
\hline DurableGoodsOrdersF & $\begin{array}{c}0.0386 \\
(0.0650)\end{array}$ & $\begin{array}{c}0.156 \\
(0.179)\end{array}$ & $\begin{array}{c}-0.000643 \\
(0.0361)\end{array}$ & $\begin{array}{l}0.0477 \\
(0.100)\end{array}$ \\
\hline ConstructionSpending & $\begin{array}{c}-0.0449 \\
(0.192)\end{array}$ & $\begin{array}{c}0.168 \\
(0.530)\end{array}$ & $\begin{array}{r}-0.0856 \\
(0.107)\end{array}$ & $\begin{array}{c}0.0563 \\
(0.297)\end{array}$ \\
\hline BusinessInventories & $\begin{array}{c}0.289 \\
(0.447)\end{array}$ & $\begin{array}{c}0.257 \\
(1.231)\end{array}$ & $\begin{array}{r}-0.0441 \\
(0.248)\end{array}$ & $\begin{array}{l}-0.658 \\
(0.689)\end{array}$ \\
\hline GovernmentBudgetDeficit & $\begin{array}{c}0.0873 \\
(0.0625)\end{array}$ & $\begin{array}{c}0.113 \\
(0.172)\end{array}$ & $\begin{array}{c}0.0749 * * \\
(0.0347)\end{array}$ & $\begin{array}{c}0.0794 \\
(0.0965)\end{array}$ \\
\hline TradeBalance & $\begin{array}{c}-0.163^{* * *} \\
(0.0622)\end{array}$ & $\begin{array}{c}-0.472^{* * *} \\
(0.171)\end{array}$ & $\begin{array}{l}-0.0524 \\
(0.0346)\end{array}$ & $\begin{array}{l}-0.167^{*} \\
(0.0961)\end{array}$ \\
\hline PPI & $\begin{array}{c}0.0867 \\
(0.0661)\end{array}$ & $\begin{array}{c}0.166 \\
(0.182)\end{array}$ & $\begin{array}{c}0.0809^{* *} \\
(0.0367)\end{array}$ & $\begin{array}{c}0.150 \\
(0.102)\end{array}$ \\
\hline ConsumerPriceIndex & $\begin{array}{c}0.0151 \\
(0.0655)\end{array}$ & $\begin{array}{c}-0.0466 \\
(0.181)\end{array}$ & $\begin{array}{l}0.00149 \\
(0.0364)\end{array}$ & $\begin{array}{r}-0.0841 \\
(0.101)\end{array}$ \\
\hline NAPMIndex & $\begin{array}{r}-0.0167 \\
(0.193)\end{array}$ & $\begin{array}{c}-0.326 \\
(0.531)\end{array}$ & $\begin{array}{l}0.0995 \\
(0.107)\end{array}$ & $\begin{array}{c}-0.00668 \\
(0.297)\end{array}$ \\
\hline HousingStarts & $\begin{array}{l}-0.0237 \\
(0.0633)\end{array}$ & $\begin{array}{l}-0.152 \\
(0.175)\end{array}$ & $\begin{array}{c}0.0400 \\
(0.0352)\end{array}$ & $\begin{array}{c}0.0232 \\
(0.0977)\end{array}$ \\
\hline IndexOfLeadingIndicators & $\begin{array}{c}0.106^{*} \\
(0.0630)\end{array}$ & $\begin{array}{c}0.00946 \\
(0.174)\end{array}$ & $\begin{array}{c}0.0225 \\
(0.0350)\end{array}$ & $\begin{array}{l}-0.219^{* *} \\
(0.0973)\end{array}$ \\
\hline FOMC & $\begin{array}{c}-0.115 \\
(0.0854)\end{array}$ & $\begin{array}{c}-0.370 \\
(0.236)\end{array}$ & $\begin{array}{l}-0.0727 \\
(0.0474)\end{array}$ & $\begin{array}{c}-0.254^{*} \\
(0.132)\end{array}$ \\
\hline FOMCPC & $\begin{array}{l}-0.152 \\
(0.175)\end{array}$ & $\begin{array}{l}-0.511 \\
(0.484)\end{array}$ & $\begin{array}{l}-0.0468 \\
(0.0974)\end{array}$ & $\begin{array}{l}-0.222 \\
(0.271)\end{array}$ \\
\hline Constant & $\begin{array}{l}-0.0217 \\
(0.0185)\end{array}$ & $\begin{array}{c}0.0547 \\
(0.0510)\end{array}$ & $\begin{array}{l}-0.0167 \\
(0.0103)\end{array}$ & $\begin{array}{c}0.0685 * * \\
(0.0285)\end{array}$ \\
\hline Observations & 2,286 & 2,286 & 2,286 & 2,286 \\
\hline R-squared & 0.011 & 0.013 & 0.695 & 0.691 \\
\hline
\end{tabular}

This table displays the regression results from equation 4 . Standard errors are presented in parenthesis. */**/*** indicates statistical significance at the 10/5/1 percent level. 
Table 3: Regression results grouped announcements

\begin{tabular}{lcccc}
\hline & $(1)$ & $(2)$ & $(3)$ & $(4)$ \\
VARIABLES & $\Delta \mathrm{VTS}$ & $\Delta \mathrm{VTS}$ & $\Delta \mathrm{VTS}$ & $\Delta \mathrm{VTS}$ \\
\hline \multirow{2}{*}{ price_news } & 0.0516 & & $0.0481^{*}$ & \\
& $(0.0453)$ & & $(0.0251)$ & \\
real_side_news & -0.0408 & & 0.0108 & \\
monetary_policy_news & $(0.0380)$ & & $(0.0211)$ & \\
& $-0.155^{* *}$ & & $-0.0803^{*}$ & \\
any_news & $(0.0744)$ & & $(0.0413)$ & \\
& & -0.00970 & & 0.0123 \\
return & & $(0.0266)$ & & $(0.0147)$ \\
& & & $-0.00210^{* * *}$ & $-0.00210^{* * *}$ \\
Constant & -0.0174 & -0.0178 & -0.00895 & -0.0125 \\
& $(0.0148)$ & $(0.0200)$ & $(0.00822)$ & $(0.0111)$ \\
Observations & & & & \\
R-squared & 2,286 & 2,286 & 2,286 & 2,286 \\
\hline
\end{tabular}

This table displays the regression results from equation 4 when announcements are grouped according to Beechey \& Wright (2009). Price news include PPI and Consumer Price Index, real side news include GDP Advance, GDP Preliminary, GDP Final, Industrial Production, Capacity Utilization and the NAPM Index and monetary policy news is the FOMC with or without a press conference. Standard errors are presented in parenthesis. $* / * * / * * *$ indicates statistical significance at the $10 / 5 / 1$ percent level. 
Table 4: Regression results with policy uncertainty

\begin{tabular}{|c|c|c|c|c|}
\hline VARIABLES & $\begin{array}{c}(1) \\
\Delta \mathrm{VTS}\end{array}$ & $\begin{array}{c}(2) \\
\Delta \text { VTS }\end{array}$ & $\begin{array}{c}(3) \\
\Delta \mathrm{VTS}\end{array}$ & $\begin{array}{c}(4) \\
\Delta \mathrm{VTS}\end{array}$ \\
\hline price_news & $\begin{array}{l}-0.146 \\
(0.149)\end{array}$ & $\begin{array}{l}-0.0718 \\
(0.0827)\end{array}$ & $\begin{array}{l}-0.0757 \\
(0.0824)\end{array}$ & $\begin{array}{l}-0.210^{* *} \\
(0.0972)\end{array}$ \\
\hline real_side_news & $\begin{array}{c}0.171 \\
(0.128)\end{array}$ & $\begin{array}{l}0.232^{* * *} \\
(0.0707)\end{array}$ & $\begin{array}{l}0.223^{* * *} \\
(0.0704)\end{array}$ & $\begin{array}{l}0.295^{* * * *} \\
(0.0831)\end{array}$ \\
\hline monetary_policy_news & $\begin{array}{r}-0.0456 \\
(0.251)\end{array}$ & $\begin{array}{c}0.153 \\
(0.139)\end{array}$ & $\begin{array}{c}0.155 \\
(0.139)\end{array}$ & $\begin{array}{c}0.278^{*} \\
(0.160)\end{array}$ \\
\hline News_Based_Policy_Uncert & $\begin{array}{c}0.000338 \\
(0.000342)\end{array}$ & $\begin{array}{c}0.000219 \\
(0.000189)\end{array}$ & $\begin{array}{l}-4.99 \mathrm{e}-05 \\
(0.000197)\end{array}$ & $\begin{array}{l}-5.00 \mathrm{e}-05 \\
(0.000198)\end{array}$ \\
\hline price_news*Policy_Uncert & $\begin{array}{c}0.00149 \\
(0.00105)\end{array}$ & $\begin{array}{c}0.000919 \\
(0.000581)\end{array}$ & $\begin{array}{c}0.000952 \\
(0.000579)\end{array}$ & $\begin{array}{c}0.000364 \\
(0.000610)\end{array}$ \\
\hline real_side_news*Policy_Uncert & $\begin{array}{l}-0.00159^{*} \\
(0.000907)\end{array}$ & $\begin{array}{c}-0.00166^{\text {**** }} \\
(0.000503)\end{array}$ & $\begin{array}{c}-0.00160^{* * *} \\
(0.000500)\end{array}$ & $\begin{array}{c}-0.00139 * * * \\
(0.000519)\end{array}$ \\
\hline monetary_policy_news*Policy_Uncert & $\begin{array}{l}-0.000811 \\
(0.00173)\end{array}$ & $\begin{array}{l}-0.00169^{*} \\
(0.000959)\end{array}$ & $\begin{array}{l}-0.00171^{*} \\
(0.000954)\end{array}$ & $\begin{array}{r}-0.000933 \\
(0.00103)\end{array}$ \\
\hline price_news*vix & & & & $\begin{array}{c}0.0122^{* * * *} \\
(0.00448)\end{array}$ \\
\hline real_side_news*vix & & & & $\begin{array}{l}-0.00580 \\
(0.00365)\end{array}$ \\
\hline monetary_policy_news*vix & & & & $\begin{array}{l}-0.0132^{*} \\
(0.00767)\end{array}$ \\
\hline return & & $\begin{array}{c}-0.00210^{* * *} \\
(2.92 \mathrm{e}-05)\end{array}$ & $\begin{array}{c}-0.00207^{* * *} \\
(2.97 \mathrm{e}-05)\end{array}$ & $\begin{array}{c}-0.00207^{* * * *} \\
(2.97 \mathrm{e}-05)\end{array}$ \\
\hline vix & & & $\begin{array}{c}0.00563^{* * *} \\
(0.00121)\end{array}$ & $\begin{array}{c}0.00573^{* * *} \\
(0.00133)\end{array}$ \\
\hline Constant & $\begin{array}{l}-0.0634 \\
(0.0489)\end{array}$ & $\begin{array}{l}-0.0390 \\
(0.0271)\end{array}$ & $\begin{array}{c}-0.101^{* * *} \\
(0.0301)\end{array}$ & $\begin{array}{c}-0.102^{* * *} \\
(0.0307)\end{array}$ \\
\hline Observations & 2,286 & 2,286 & 2,286 & 2,286 \\
\hline R-squared & 0.005 & 0.695 & 0.698 & 0.699 \\
\hline
\end{tabular}

This table displays the regression results from equation 5 when announcements are grouped according to Beechey \& Wright (2009). Price news include PPI and Consumer Price Index, real side news include GDP Advance, GDP Preliminary, GDP Final, Industrial Production, Capacity Utilization and the NAPM Index and monetary policy news is the FOMC with or without a press conference. Standard errors are presented in parenthesis. $* / * * / * * *$ indicates statistical significance at the 10/5/1 percent level. 


\title{
Macro news and long-run volatility expectations
}

\begin{abstract}
ANDERS VILHELMSSON
I propose a new model-free method for estimating long-run changes in expected volatility using VIX futures contracts. The method is applied to measure the eect on stock market volatility of scheduled macroeconomic news announcements. I nd that looking at long-run changes gives qualitatively dierent results compared to previous studies that only look at realized variance and the VIX. I further nd that FOMC announcements on average resolve uncertainty, but only during times when policy uncertainty is higher than average. Real side macro announcements increase long-run volatility during times of low policy uncertainty, but the eect is reversed during times of high policy uncertainty.
\end{abstract}

\section{KEYWORDS:}

THE KNUT WICKSELL CENTRE FOR FINANCIAL STUDIES

The Knut Wicksell Centre for Financial Studies conducts cutting-edge research in financial economics and related academic disciplines. Established in 2011, the Centre is a collaboration between Lund University School of Economics and Management and the Research Institute of Industrial Economics (IFN) in Stockholm. The Centre supports research projects, arranges seminars, and organizes conferences. A key goal of the Centre is to foster interaction between academics, practitioners and students to better understand current topics related to financial markets. 